\title{
"ThINKING" IN A DEWEYAN Perspective: The Law School EXAM as a CASE STUdy FOR THINKING IN LAWYERING
}

\author{
Donald J. Kochan*
}

\begin{abstract}
As creatures of thought, we are thinking all the time, but that does not necessarily mean that we are thinking well. Answering the law school exam, like solving any problem, requires that the student exercise thinking in an effective and productive manner. This Article provides some guidance in that pursuit. Using John Dewey's suspended conclusion concept for effective thinking as an organizing theme, this Article presents one basic set of lessons for thinking through issues that arise regarding the approach to a law school exam. This means that the lessons contained here help exercise thought while taking the exam-to think through the exam approach. The second more subtle purpose is to demonstrate that the law school exam can serve as a case study in the effectiveness of certain thinking tools that have much broader application. For that reason, this Article is not your typical "how-to" guide, but instead provides guidance critically and generally applicable to the thinking enterprise itself.
\end{abstract}

\section{INTRODUCTION}

As creatures of thought, we are thinking all the time, but that does not necessarily mean that we are thinking well. Answering the law school exam, like solving any problem, requires the student to think in an effective and productive manner. This Article provides some guidance in that pursuit.

In How We Think, ${ }^{1}$ the influential John Dewey proclaims that "the most important factor in the training of good mental habits consists in acquiring the attitude of suspended conclusion." ${ }^{2}$ This Article is organized around that statement and its applicability to problem-solving approaches, with a particular

* Professor of Law, Chapman University School of Law. J.D., Cornell Law School, 1998; B.A. Western Michigan University, 1995. I thank the participants at an October 2010 Chapman University School of Law faculty workshop and Mario Mainero for helpful comments. I also thank Jennifer Spinella for her comments and tremendous support.

1 John Dewey, How We Think (1910) [hereinafter "Dewey"]; see also John Dewey, How We Think: A Restatement of the Relation of Reflective Thinking to the Educative Process (1933), reprinted in 8 John Dewey, The later works, 1925 - 1953: Essays AND How We Think, Revised Edition (Jo Ann Boydston ed., 2008) [hereinafter "Dewey 1933"].

2 Dewey, supra note 1 , at 13. 
emphasis on thinking as demonstrated in an answer to a traditional law school essay exam question.

The concept of suspended conclusion-the concept that serves as the constant weaved throughout this Article's analysis-means that the thinker must approach every problem with an open mind, without a predetermined conclusion. One attains "the attitude of suspended conclusion" by applying a discipline that evades our natural desires and tendencies to rush to conclusions. The concept aids the evaluator of a problem in the pursuit of a full and rich answer, and the attitude of suspended conclusion is a valuable asset regardless of what type of problem one must address. Although written as advice to a law school exam taker, the tips in this Article should have value for thinkers of all types, especially in determining how one communicates thinking to someone not privy to his "mind's wheel."

This Article is about taking a law school exam, but only as a case study for a broader lesson in legal thinking. Using Dewey's suspended conclusion concept as an organizing theme, this Article presents one basic set of lessons for thinking through issues regarding the approach to a law school exam, meaning that the lessons contained here help students learn to exercise thought while taking the exam-to think through their exam approach. As a result, the law school exam can serve as a case study for the effectiveness of certain thinking tools that have much broader application-such as examining the process of lawyerly thinking itself through one example: the law school exam. This Article uses the law school exam to demonstrate how thinking in a suspended conclusion is important to law students and attorneys alike as it is critical to effective lawyering.

For that reason, this Article is not your typical "how-to" guide. This Article is meant for law students seeking guidance in exam-taking. It is for law teachers who may support some of these same approaches to exam-taking and wish to find support for their theories. It can also serve as supplemental course material that teachers can provide to students to explain their evaluative approach. And finally, it is generally applicable as the law exam is just one case study in how effective thinking habits can transform the problem-solving enterprise. In this last category, there is material in this Article that should be useful to judges, lawyers, and members of all occupations who seek to think through a difficult problem, reach a reasoned conclusion, and communicate their processes and results effectively to others.

There is no dearth of published material aimed at assisting law students, and much of it purports to reveal successful law school exam writing techniques. ${ }^{3}$ Many tips contained herein are reflected in other exam-taking books, articles, and materials. ${ }^{4}$ This Article does not endorse, incorporate, or critically review this mass of "how-to" advice already available. The guidance in this

3 See generally, e.g., Donald J. Kochan, "Learning" Research and Legal Education: A Brief Overview and Selected Bibliographical Survey, 40 Sw. L. Rev. 449 (2011) (listing sources); Barry Friedman \& John C.P. Goldberg, Open Book: Succeeding on Exams from the First Day of Law School (2011).

4 Although, this Article has not aimed to collect, organize, explicitly adopt, or distinguish when appropriate those materials within this presentation. 
Article is unique because it concentrates on these approaches as they fit within the suspended conclusion theme and framework.

All exam-taking assistance materials are, of course, fraught with danger as there is little guarantee that the techniques taught by detached strangers will satisfy the evaluative proclivities of individual professors. Reliance on secondary sources for discerning the preferences of the professors can indeed backfire in much the same way that a student's excessive reliance on commercial outlines inure to the detriment of the individualized curriculum in assigned texts and classroom activity. Such reliance risks over-inclusive, under-inclusive, or even contradictory absorption of the subject matter taught. This Article recognizes the utility of only cautious consumption of such aids, including this Article.

As far as the Article relates to guidance on approaching a law school exam, it is not intended to be universally applicable - there are variations in how students learn, how professors teach, and how professors evaluate student performance based on methodological expectations. Thus, this Article will attempt to keep most of the analysis close to those approaches that are nearuniversally valuable in tackling law school exam problems. Hopefully, the guidance in this Article can at least serve as a starting point for understanding some generally accepted points to begin building an exam-taking model tailored to each professor's preferences. As such, professors may adopt, reject, or refine appropriately the guidance provided, and students must remain vigilantly aware of that fact.

Part I of this Article provides a brief summary of the meaning and utility of adopting an attitude of suspended conclusion in the act of thinking generally. Although the concept is advocated by many authors in one way or another, the Part maintains the theme and focus of Dewey's formulation of the concept to present a cohesive package. Part II then sets forth several broad categories of guidance in the approach to a law school exam-thereby explaining the utility of the attitude of suspended conclusion in one area of operation. The Article concludes that an attitude of suspended conclusion will emerge as a desirable trait to adopt and apply in the problem-solving enterprise.

\section{A Brief Summary of Dewey's "Attitude of SuSPENDED CONClusion"}

Dewey's How We Think stands as one of the most important works in education even one hundred years after its publication. ${ }^{5}$ It guides students and teachers through their "thinking problems" that serve as obstacles to effective problem solving. ${ }^{6}$ As such obstacles are omnipresent in legal education, Dewey's insights fit well with any pedagogical endeavor in advancing a law

5 The Author has analyzed and explained Dewey's concept of an "attitude of suspended conclusion" at considerable length elsewhere, and will only summarize some of the salient features of the attitude for this Article's purposes. See Donald J. Kochan, Thinking Like Thinkers: Is the Art and Discipline of an "Attitude of Suspended Conclusion" Lost on Lawyers?, 35 Seattle L. Rev. 1 (2011).

6 "Teachers of all kinds will find [How We Think] a source of stimulus and enlightenment . . . B.H. Bode, Book Review, 18 Sch. Rev. 642, 645 (1910). 
school's mission to produce effective lawyers. ${ }^{7}$ The most noteworthy contribution in How We Think is Dewey's emphasis on the necessity for adopting the attitude of suspended conclusion to accomplish effective thinking.

The dominant premise in How We Think is that the mind must learn to suspend conclusion — to suspend judgment — at the outset of any approach to a problem. Dewey's explanation of "reflective thought"-meaning situations where "the ground or basis for a belief is deliberately sought and its adequacy to support the belief examined"8 — sets the basis for analysis of this suspended conclusion concept. The critical paragraph from How We Think for purposes of the remaining discussion in this Article explains the pivotal importance of the suspended conclusion concept:

Reflective thinking, in short, means judgment suspended during further inquiry; and suspense is likely to be somewhat painful. As we shall see later, the most important factor in the training of good mental habits consists in acquiring the attitude of suspended conclusion, and in mastering the various methods of searching for new materials to corroborate or to refute the first suggestions that occur. To maintain the state of doubt and to carry on systematic and protracted inquiry-these are the essentials of thinking. 9

This reflective process facilitates the effective thinking most law school exam takers and legal writers of all types hope to accomplish.

Dewey describes the attitude and its states of doubt, confusion, and perplexity as creating an "alert, cautious, and thorough inquiry." ${ }^{10}$ In describing that meaning of the term "reflection" as used in How We Think, one commentator explains that " $[\mathrm{t}] \mathrm{o}$ reflect means to turn the matter over in the mind, to view it from various angles, [and] to consider carefully the various possibilities of solution." 11 The thinker must discipline himself to adopt the attitude that makes this careful consideration possible.

Patience combined with a capacity and desire to pause before reaching a conclusion form the foundation of the attitude. ${ }^{12}$ The basics behind the attitude of suspended conclusion include the following demands of the thinker at the outset of a problem-solving exercise and then throughout the process: embrace doubt, accept confusion and anxiety, examine alternative suggestions, overcome impatience and habitual tendencies to rush toward an answer, and otherwise avoid the impulsive tendencies toward a premature conclusion before

7 John Dewey, An Analysis of Reflective Thought, 19 J. PHIL. 29, 29 (1922) [hereinafter Analysis of Reflective Thought] (How We Think "was written for pedagogical purposes rather than for strictly logical ends.").

8 Dewey, supra note 1, at 1-2.

$9 I d$. at 13. Dewey describes this attitude as the foundation of thought: "The essence of critical thinking is suspended judgment; and the essence of this suspense is inquiry to determine the nature of the problem before proceeding to attempts at its solution. This, more than any other thing, transforms mere inference into tested inference, suggested conclusions into proof." Id. at 74 .

$10 \mathrm{Id}$. at 62.

11 Samuel Chester Parker, Problem-Solving or Practice in Thinking. I, 21 Elementary ScH. J. 16, 25 (1920) (paraphrasing Dewey).

12 John Georgeoff, Man or Automaton, 44 Peabody J. Educ. 143, 143 (1966) ("When significant problems arise . . a rational man pauses first to think and then to act."). 
adequate reasoning. ${ }^{13}$ The attitude of suspended conclusion, stripped to its basics, means that a thinker must start with a feeling that there is not a clear answer to a problem. If their intuition is to the contrary then they must force themselves to feel doubt, confusion, or perplexity-without which they will never engage in an honest, thorough, and searching inquiry about the best solution. If they are convinced too early of an answer, they will not find, let alone consider, alternatives because of their narrow focus.

Dewey then suggests that the thinker must identify one possible conclusion to the difficulty identified in a problem. This can be either the person's initial intuition or some other possible conclusion. Once that suggestion has been identified, the thinker must then search for, consider, test, and evaluate rival (or alternative) suggestions. ${ }^{14}$ Then, Dewey claims, all rival suggestions must be compared and contrasted before reaching a final conclusion. ${ }^{15}$

Dewey explains that "suspended belief, or the postponement of a final conclusion pending further evidence, depends partly upon the presence of rival conjectures as to the best course to pursue or the probable explanation to favor." 16 One cannot be narrow-minded and stuck in the pursuit of a definite answer, be predisposed to his or her favored answer, or be settled too early on the first suggestion. Instead, "cultivation of a variety of alternative suggestions" is a necessary and important factor in a proper attitude aimed toward effective thinking. ${ }^{17}$

Dewey summarizes these steps, explaining that "[r]eflective thinking . . involves (1) a state of doubt, hesitation, perplexity, mental difficulty, in which thinking originates, and (2) an act of searching, hunting, inquiring, to find material that will resolve the doubt, settle and dispose of the perplexity." 18 The process is very similar to what one commentator calls "disciplined curiosity." 19 In many ways, the process is very much like the position of a judge in a trial court who must listen to all sides, give each a fair opportunity in his delibera-

\footnotetext{
13 Dewey, supra note 1, at 14-15 ("Instead of being pushed into a mode of action by the sheer urgency of forces, whether instincts or habits, of which he is not aware, a reflective agent is drawn (to some extent at least) to action by some remoter object of which he is indirectly aware."); see also Nelson P. Miller \& Bradley J. Charles, Meeting the Carnegie Report's Challenge to Make Legal Analysis Explicit-Subsidiary Skills to the IRAC Framework, 59 J. Legal Educ. 192, 202 (2009) ("The central aspect of critical reasoning is the commitment and ability to be persuaded by reasons rather than by personality, prejudice, power, chance, or other factors.").

14 Dewey, supra note 1, at 30 ("Thinking involves (as we have seen) the suggestion of a conclusion for acceptance, and also search or inquiry to test the value of the suggestion before finally accepting it.").

15 Id. at 89-90; see infra text accompanying note 68.

16 Dewey, supra note 1, at 75.

17 Id. (emphasis omitted).

18 Dewey 1933, supra note 1, at 120-21 (emphasis omitted); see also Dewey, supra note 1, at 9 .

19 Richard K. Neumann, Jr., A Preliminary Inquiry into the Art of Critique, 40 Hastings L.J. 725, 746-47 (1989).
} 
tion, and come to a conclusion only after a full hearing from all parties with competing arguments. ${ }^{20}$

Eventually, the search and analysis must end and the thinker must settle on some conclusion, particularly as dictated by necessary time or resource constraints. As Dewey acknowledges, "There is such a thing as too much thinking, as when action is paralyzed by the multiplicity of views suggested by a situation. . . . The best mental habit involves a balance between paucity and redundancy of suggestions." ${ }^{21}$ Over-extended suspension can itself yield problems, and the attitude of suspended conclusion anticipates the need for judgment in knowing when to conclude after comparing and contrasting the rival suggestions.

In the law school exam context, adherence to an attitude of suspended conclusion is simply an application of a generally applicable and useful way of thinking, adapted to the situation. The attitude of suspended conclusion must be cultivated, accepted, and then applied when faced with problem solving.

As one commentator states while referencing Dewey, "The teacher should encourage pupils to maintain an attitude of suspended conclusion or suspended judgment ... in order to provide for a thorough canvass of the problem but also in order to obviate bias which may interfere with the thinker's selection and evaluation of data or evidence." 22 Educators should encourage effective thinking and help students overcome obstacles preventing rigorous adherence to the attitude of suspended conclusion. ${ }^{23}$

Finally, Dewey emphasizes that adopting an attitude of suspended conclusion works " $[\mathrm{b}] \mathrm{y}$ putting the consequences of different ways and lines of action before the mind, [enabling] us to know what we are about when we act. It converts action that is merely appetitive, blind, and impulsive into intelligent action." ${ }^{24}$ Some natural tendencies or negative habits of mind can preclude effective thinking. They must be overcome and replaced with a positive habitan attitude of suspended conclusion. The next Part helps guide the student and all thinkers alike toward adopting the attitude of suspended conclusion and displacing the bad habits that hinder effective thinking and positive performance in the law school exam.

\section{Approaching a Law School Exam From a Deweyan Perspective}

The law school examination is a unique situation, but it provides an interesting case study on the application of Dewey's attitude of suspended conclu-

20 Dewey, supra note 1, at 102 ("Cases brought to trial before a judge illustrate neatly and unambiguously this strife of alternative interpretations; but any case of trying to clear up intellectually a doubtful situation exemplifies the same traits.").

21 Dewey, supra note 1, at 36.

22 Samuel Chester Parker, Methods of Teaching in High Schools 194 (rev. ed. 1920).

23 Peter H. Martorella, Reflective Thinking and the American Culture, 45 Peabody J. Educ. 87, 90 (1967) (calling on "those individuals who are operating in the society to stimulate thinking in all facets of life among all individuals" to assume a leading role in guiding thinking skills).

24 Dewey 1933, supra note 1, at 125 (emphasis omitted). 
sion and it is a forum where adopting the attitude works well in practice. Whether or not a law student aims to adopt an attitude of suspended conclusion, even the simply self-interested and grade-optimizing law student should choose to at least recognize that adoption of the attitude while sitting for the law school exam has substantial utility.

It is advisable to adopt an attitude of suspended conclusion to generally become a better thinker, but a student might choose to do so for a much simpler and immediate reason: better answers and better grades. Regarding teaching the student his "techniques for focusing," Professor Richard Coe explains that "an attitude [of suspended conclusion] . . . generally secures excellent, as opposed to merely good, grades." ${ }^{25}$ The self-interested and rational grade-optimizer will find that adopting an attitude of suspended conclusion is a smart and optimal decision in the exam context.

In a recent and interesting 2009 article, Professors Nelson Miller and Bradley Charles address some related subjects when they seek to "add[ ] to the discussion of IRAC by identifying and illustrating many of the subsidiary skills that students must acquire to effectively use the oversimplified IRAC framework." ${ }^{26}$ Among the skills identified there are: thinking, reading, conceptualizing, reasoning, generalizing, specifying, hypothesizing, deducing, inducing, abducing, evaluating, contrasting, scaling, satisfying, weighing, and quantifying. ${ }^{27}$

What follows should not be misconstrued as IRAC. The points that follow apply more broadly, although a student could certainly apply these lessons to the IRAC format should the professor ask for a strict adherence to it; each student must know the stylistic preferences of each evaluator.

Some professors will prefer a structured IRAC product, others a more flowing essay-type product, others a narrative product, and still others a variety of product-types tailored to the particular consuming evaluator-professor. The discerning student should inquire as to the preferences of each particular professor before developing any specific approach. Presume that each exam is different and that each professor has distinct expectations. The guidance in this Part is provided in the hope that it has utility while remaining flexible such that educators can modify it to fit their curriculum. At the same time, it is meant to show a situational application of the suspended conclusion concept.

So, what follows are this Author's expectations on a "traditional" law school essay exam. ${ }^{28}$ However, they are likely congruous, in whole or in part,

25 Richard M. Coe, If Not to Narrow, Then How to Focus: Two Techniques for Focusing, 32 C. Composition \& Comm. 272, 276 (1981) (citing Mina Shaughnessy, Errors and Expectations 227 (1977)); see also Neumann, supra note 19, at 747 n.67 (“[M]uch student writing reflects the misconception that an argument is nothing more than a random collection of comments that seem favorable to the proposed conclusion.").

26 Miller \& Charles, supra note 13, at 193. Miller and Charles cite Dewey's How We Think a few times but only in a limited context as support for the claim that students need to have a "myriad of skills" to effectively use IRAC and do not discuss suspended conclusion. Id. at nn.7, 13, 52, 73.

27 Id. at 194-218.

28 As used here, "traditional law school essay exam" means one in which the student is given a hypothetical problem based on a closed set of facts; where some dispute or legal controversy is implied from the existence of competing interests or parties; where the student 
with the expectations of many of the Author's law school academic colleagues. Several studies have been done on the form and substance of law school exams ${ }^{29}$ including analyses of the elements in a so-called "traditional" exam and the benefits and deficiencies of such an evaluation approach. ${ }^{30}$

This Part claims neither a monopoly on the wisdom of exam-taking techniques nor pretention to prescribe any exact model of approach. It explains why the attitude of suspended conclusion has particular utility in the law school exam process, at least for those exams where instructors operate with the same or similar evaluative metrics as this Author. It might be said that it encourages one positive "habit of exam taking," and fills a gap in legal argument architecture between a problem and its solution. Finally, what follows is certainly not exhaustive of the guidance for answering a law school exam. Instead, the remainder of this Article is simply a selection of guidance that is most closely related to the exam taker's ability to make the attitude of suspended conclusion effective in operation.

\section{A. Suspend Conclusion}

When approaching a problem like a law school exam, the most important lesson is to begin with an attitude of suspended conclusion. A student who begins with a conclusion in mind and is set on its accuracy before he writes the analysis of the question will be doomed to cut short the analysis. The answer is

is asked either impliedly or explicitly to evaluate and resolve all or specific disputes or controversies that arise from the facts; where the student is expected to apply a relatively closed set of law and lessons learned from the specific class for which the exam is administered; where the professor may either ask for a comprehensive analysis of the situation or may confine or channel the student's answer through the use of pinpoint questions or direction to specific laws or doctrines; and where the student is expected to write her answer in an essay form of one kind or another in a bluebook or electronic equivalent within designated time constraints. For purposes of this Part, it does not seem relevant whether the available materials (notes, books, etc.) for reference is limited by the open or closed nature of the process or whether the student acts as an individual or in a collaborative capacity.

${ }_{29}$ As distinguished from earlier discussions regarding articles designed to assist students in taking exams.

30 See, e.g., Robert C. Downs \& Nancy Levit, If It Can't Be Lake Woebegone ... A Nationwide Survey of Law School Grading and Grade Normalization Practices, 65 UMKC L. REv. 819, 822 (1997) (explaining that "[t]he typical law school examination is a single, end-ofsemester or end-of-course test on which most or all of the course grade is based," but criticizing the one shot, one grade approach to law school evaluation); Kenney F. Hegland, On Essay Exams, 56 J. Legal Educ. 140, 140 (2006) (defending the essay exam as in important tool for developing and evaluating writing skills); Philip C. Kissam, The Ideology of the Case Method/Final Examination Law School, 70 U. CIN. L. Rev. 137, 153 (2001) (describing the traditional law school exam and explaining "[t]his system imposes a single timelimited examination at the end of the semester that covers the course material 'comprehensively' by posing a series of novel problems that students must resolve under considerable time pressure"); Philip C. Kissam, Law School Examinations, 42 VAnd. L. Rev. 433, 435 (1989) (“This Essay provides a 'systemic analysis' and a 'total critique' by assessing the structure, contextual relationships, values, and adverse effects of law school examinations."); Steve Sheppard, An Informal History of How Law Schools Evaluate Students, with a Predictable Emphasis on Law School Final Exams, 65 UMKC L. REv. 657 (1997) (an analysis of the history and evolution of the examination process in law schools); see also Richard B. Amandes, How We Examine, 11 J. Legal Educ. 566 (1959); Steve H. Nickles, Examining and Grading in American Law Schools, 30 Ark. L. Rev. 411, 411-12 (1977). 
destined to be incomplete if either one's thinking, or more importantly, one's memorialization of thought (which is the only way to show thought on a written exam), ${ }^{31}$ is frozen in a predestined course with an inflexible commitment to a pre-formed conclusion.

Too often students become set on a course for which there is no turning back. This can occur on multiple levels. One level might be in prematurely setting the mind on a specific "right answer" and thus foreclosing alternative arguments. Another level, however, is equally dangerous if not more so. This second danger occurs when a student becomes close-minded about the issue itself - the concept the professor is testing, and the student must identify.

When students "spot" an issue, they must subject that spotting to the same rigorous review that they give their resolution of that issue. The student must suspend conclusion on the matter of whether that one issue is the only issue possibly raised by the set of facts. When students spot an issue, they should stop and ask: Might there be another, additional, or distinct issue raised? Am I confident that the first issue to come to mind is indeed the only issue evoked by the problem, and therefore the only issue to address?

The exam taker must embrace that state of doubt about an answer and overcome the anxiety that leads to premature conclusions. ${ }^{32}$ As Dewey writes:

The method that is employed in discovery, in reflective inquiry, cannot possibly be identified with the method that emerges after the discovery is made. In the genuine operation of inference, the mind is in the attitude of search, of hunting, of projection, of trying this and that; when the conclusion is reached, the search is at an end. ${ }^{33}$

Many students, whether they recognize it or not, face habitual barriers to adopting an attitude of suspended conclusion on an exam and in other endeavors. There exists a tendency on the part of many to rush toward closure because they are stuck with what Dewey calls a "dogmatic habit of mind." 34 Dewey explains:

To many persons both suspense of judgment and intellectual search are disagreeable; they want to get them ended as soon as possible. They cultivate an over-positive and dogmatic habit of mind, or feel perhaps that a condition of doubt will be regarded as evidence of mental inferiority. It is at the point where examination and test enter into investigation that the difference between reflective thought and bad thinking comes in. To be genuinely thoughtful, we must be willing to sustain and protract that state of doubt which is the stimulus to thorough inquiry, so as not to accept an idea or make positive assertion of a belief until justifying reasons have been found. ${ }^{35}$

These tendencies must be overcome. To do so, we must first harness an awareness that they exist and recognize the harm they cause, and then we must actively pursue an attitude of suspended conclusion. Only then can we replace the debilitating tendencies with those positive habits required for good thinking.

The dogmatic habit of mind arises, in part, because many law students come to law school with misguided beliefs that there are "right" answers in law

31 See infra text accompanying note 53.

32 See supra text accompanying note 16.

33 Dewey, supra note 1, at 112 (emphasis omitted).

34 Dewey 1933, supra note 1, at 124.

35 Id. 
school. ${ }^{36}$ Quite often there are not, and it is dangerous to start the problemsolving process believing there necessarily is a correct and final definitive answer or conclusion. ${ }^{37}$ Edward Levi famously warns: "In an important sense legal rules are never clear, and, if a rule had to be clear before it could be imposed, society would be impossible." 38 If students grasp this reality, they are in a better position to fully analyze a problem and search within and between rival suggestions of a conclusion.

The law school exam taker can move from confusion to a greater sense of clarity, but only if he starts with the humble recognition of these realities and the utility of approaching the problem with suspended conclusion. After suspending conclusion, Dewey's insights on effective thinking provide additional counsel applicable to the law school exam taker.

\section{B. Read the Question and Understand What is Asked and What is Not; Consider the Facts a Closed Set}

Nothing is more basic than the fact that you cannot provide a responsive answer if you do not know what is asked. Thus, the exam taker should be sure to read the question before starting to answer-nothing could be more impulsive than answering before that step.

Part of this task is to understand and discern what is asked. As such, it is often useful to take a moment while outlining an answer to explicitly write down and acknowledge to oneself what is not asked. By doing so, one can avoid diversions or concerns about unstated facts. Remember that mental focus early will translate into a focused written answer. In the setting of a law school exam with time constraints, the lack of focus can be deadly.

Also remember that the question is a request for an answer, and the evaluator sets forth the expectations upon which the response will be judged. Consider the evaluator the customer and the student the provider of goods or services. If the professor orders takeout beef and when he opens the bag (the bluebook exam) at home and sees that he got chicken (an answer addressing a different question), he is not likely to rate the product highly on his customer satisfaction survey (the grade), even if the restaurant thought that chicken was the correct dish. The professor, like the discerning customer, has expectations and evaluates performance based on the product she has asked to receive.

The facts should be considered a closed set, unless told otherwise. The student must look for alternative suggestions ${ }^{39}$ within the closed problem set. But that does not mean one should not point out where there is insufficient information to assess the situation. In such a case, the best approach is to work

36 Professors Lisa McElroy and Christine Coughlin have concluded that "the vast majority of [law] students have been educated in environments where there is a right and wrong answer ... . [and] may tend automatically to return to the mindset that there must be a 'correct' response to the legal question presented." Lisa T. McElroy \& Christine N. Coughlin, The Other Side of the Story: Using Graphic Organizers to Counter the Counter-Analysis Quandary, 39 U. BALt. L. Rev. 227, 233 (2010).

37 Dewey, supra note 1, at 49-50 (discussing the risks of starting from the position of finding a "right" answer).

38 Edward H. Levi, An Introduction to Legal Reasoning 1 (1949).

39 See infra text accompanying notes 67-75. 
with the facts given and, only in limited circumstances, provide alternative analyses regarding how things may change if one had more information. Reckless speculation about "but if" scenarios cause wasteful diversions that will cost a student time and may lead the evaluator to take off points for a lack of focus. Furthermore, in the context of exams the law should be considered a somewhat closed set. In most classes, the evaluator will expect the applicable law to be focused on the subject matter of the course being tested. Thus, a student should generally avoid diversions into material from other classes.

\section{Demonstrate Relevancy; Discernment is Key}

On many law school exam questions, the evaluator is testing a student's legal analysis abilities, to which the skills of spotting issues, demonstrating relevance of statements, and exercising discernment are vital. ${ }^{40}$ This Article contends that the skills associated with relevancy and discernment are among the important ways, if not the most important way, that students can differentiate themselves among the pack within a curved examination.

Dewey explains that this temperament marks the good judge, which for exam purposes means the good student:

To be a good judge is to have a sense of the relative indicative or signifying values of the various features of the perplexing situation; to know what to let go as of no account; what to eliminate as irrelevant; what to retain as conducive to outcome; what to emphasize as a clue to the difficulty. This power in ordinary matters we call knack, tact, cleverness; in more important affairs, insight, discernment. . . . Possession of this ability to seize what is evidential or significant and to let the rest go is the mark of the expert, the connoisseur, the judge, in any matter. ${ }^{41}$

In another section of How We Think, Dewey explains that discernment and relevance demonstrate a discriminating mind, and the way one uses the data provided and places it in context of the analysis is a key distinguishing trait. In Dewey's words,

Every judgment is analytic in so far as it involves discernment, discrimination, marking off the trivial from the important, the irrelevant from what points to a conclusion; and it is synthetic in so far as it leaves the mind with an inclusive situation within which the selected facts are placed. ${ }^{42}$

The issue of discernment also arises where a student provides "extra" rules or information not relevant to the fact pattern or issues at bar in a question. Inclusion of such surplusage becomes a problem even when the student does not attempt to apply the irrelevant rules. An evaluator cannot help but think that the student believes the included material is relevant or that the student is unable to discern whether or not it is - that alone can lead to a point deduction for some evaluators as much as the misapplication of a relevant rule would. A student should remember that just because it is in her outline does not mean that it should be in her answer.

40 See, e.g., Miller \& Charles, supra note 13, at 212 ("Notice how important it is to legal analysis that the student effectively judge what matters and what does not matter to an evaluation. Relevance is what lawyers call the condition of mattering.").

41 Dewey, supra note 1, at 104 (emphasis omitted) (footnote omitted).

42 Id. at 114. 


\section{Do Not Outline Dump; Instead, Assess and Apply the Facts and Law}

Copying directly from an outline is the epitome of a non-thinking activity. The need to refrain from outline dumping is closely related to the importance of demonstrating relevancy and discernment. The deficiencies from outline dumping are equally present with the mere recitation of memorized material. True, there is some discernment in choosing what to regurgitate, but it is still generally just that and not much else if the memorized or outlined material is not weaved into the particular fact pattern and used, not just stated.

This has heightened importance if the examination is open book or open note because there is little demonstration of knowledge or understanding when one can simply copy rules or doctrines directly from pre-prepared materials. Also, in such situations a student should remember that if the examination is curved, all of his classmates are similarly situated and a mere outline dump does nothing to distinguish himself from his competition, who can relatively easily do exactly the same thing.

Dewey's explanations regarding choice in argument and application as vital after suspending conclusion (and analyzing between rival conclusions when embracing the state of doubt) are entirely applicable to the admonition against outline dumping. His excellent advice in this regard is worth quoting. First, he explains that in most problematic situations, one must exercise judgment to decide what is or is not relevant:

If the habit is checked, and inhibited from easy application, a possible meaning for the facts in question presents itself. No hard and fast rules decide whether a meaning suggested is the right and proper meaning to follow up. The individual's own good (or bad) judgment is the guide. There is no label on any given idea or principle which says automatically, 'Use me in this situation' - as the magic cakes of Alice in Wonderland were inscribed 'Eat me.' The thinker has to decide, to choose; and there is always a risk, so that the prudent thinker selects warily, subject, that is, to confirmation or frustration by later events. ${ }^{43}$

Dewey continues that one must be cautious in her choice of what material is relevant and ultimately contends that good thinking calls for a separate and unique set of habits, skills, and talents to determine relevance:

If one is not able to estimate wisely what is relevant to the interpretation of a given perplexing or doubtful issue, it avails little that arduous learning has built up a large stock of concepts. For learning is not wisdom; information does not guarantee good judgment. Memory may provide an antiseptic refrigerator in which to store a stock of meanings for future use, but judgment selects and adopts the one used in a given emergency - and without an emergency (some crisis, slight or great) there is no call for judgment. No conception, even if it is carefully and firmly established in the abstract, can at first safely be more than a candidate for the office of interpreter. Only greater success than that of its rivals in clarifying dark spots, untying hard knots, [and] reconciling discrepancies, can elect it or prove it a valid idea for the given situation. $^{44}$

Learning, information, and memory will never be enough to accomplish good judgment. Instead, judgment is only evident when those things are applied to the perplexity to be solved. Outline dumping skips this crucial step.

43 Id. at 106.

44 Id. at 106-07 (emphasis omitted). 
To borrow and extend Dewey's metaphor: the refrigerator (one's outline or memory) may be filled with all of the stock necessary (knowledge, rules, and experience) to make a good meal (write a good exam), but the meal cannot be the stock alone simply removed and placed on the table-instead the meal must be prepared, the right ingredients mixed in the right combinations, and the fresh new material (the facts and other data from the exam question) must be added in order to create the meal; and it still must be presented and served with the care and skill of the great chef (the essay form and analysis), and finally the product must be sold to a patron-consumer of discriminating taste (the professor-evaluator). This method is far more likely to garner a good review than would taking out the ingredients, plopping them on a table, and calling it dinner.

Instead of outline dumping or simply restating facts or giving sterile statements of legal rules unconnected to the case at hand, the effective exam taker must master the skill of assessment of the relevant law and facts and application of law to facts. Dewey prescribes that "[a]pplication is as much an intrinsic part of genuine reflective inquiry as is alert observation or reasoning itself." 45 As one English professor has written while discussing Dewey's How We Think in the context of composition, "No teacher would admit that parroting fact and the organization of fact constitute thinking." 46

A student must learn to use the facts in an exam hypothetical, not just recite them back in her answer. She must tie the facts and law together. When a professor reads a paragraph of all facts and then a paragraph of all law and then a conclusion, she is left with three segmented and disconnected parts. The student must be the engineer, putting together the raw material with his expertise to construct a bridge. A traveler has no passage across the stream if he reaches the bank and simply sees two piles of materials necessary to make that bridge. When the engineer provides only the raw materials, he has failed his commission. Or again consider that the student must be the chef who uses the ingredients and combines them through his culinary skills into a complete dish. The patron of cuisine does not go to a restaurant to be served the ingredients from the cupboard and expected to mix them together herself. When the restaurant provides the patron only the stock, neither the chef nor the waiter will receive a gratuity.

Assessment and application are vital components of good thinking and good exam taking and are critical to demonstrating that one is seriously suspending conclusion and analyzing alternative suggestions. Knowledge alone is a necessary but not sufficient condition for successful thinking. One educator explains the distinguishing characteristics of thinking in this context by asking "[m]an or automaton, which shall it be?" ${ }^{47} \mathrm{He}$ argues that "[t]o teach students factual knowledge, therefore, is not enough. They must also know how to utilize such information: They must be able to analyze, classify, select, and apply the pertinent data. This is rational thinking! Its development forms the greatest challenge and the noblest purpose of education." ${ }^{48}$ Accomplishing a task

45 Id. at 213.

46 A.L. Bader, Independent Thinking and the "Long Paper," 25 Eng. J. 667, 668 (1936).

47 Georgeoff, supra note 12, at 144.

48 Id. 
through proper assessment and application demonstrated in writing will help distinguish the good exam taker (or lawyer) from the merely knowledgeable (or transcribing) one.

\section{E. Identify Your Role and Where Appropriate Be Adaptive In It; Consider the Law a Closed Set (When Appropriate)}

Law students should constantly remember that lawyers wear many hatsincluding those of drafter, counselor, advisor, strategist, litigator, planner, anticipator, dispute avoider, etc.- -all the while remaining sensitive to the lawyer's role as an ethical professional, citizen, and leader. ${ }^{49}$

The same may be true on an exam. The question may call for, or allow, the exam taker to take one or many roles within it. Of course, the prudent exam taker must be cognizant of whether the professor-evaluator has already defined or limited the student's role. But be aware that where the role is not limited, opportunities may be present and adaptation expected for multiple roles. For example, if one finds that a conveyance is invalid under the rule against perpetuities, the student may be able to explain where the drafting error occurred and how it might have been drafted to avoid that infirmity and still satisfy the grantor's preferences.

Moreover, an appreciation for a multitude of roles can serve the exam taker well even if he has been given a specific client or role with discrete preferences or tasks in the problem. For example, any advocate must be able to anticipate the actual or potential arguments from opposing parties and therefore must wear the hat of the opposition for a bit if he is to effectively advocate or strategize his own client's position.

On a related note, law school exam takers must be adaptive in their role, recognizing the fluidity of a fact pattern and looking at the whole situation including anticipatory and litigation-avoidance mechanisms that come from the drafting and counseling roles. One author describes this as the "ability to perceive what is going on in the total environment, to understand how things connect." $" 50$ In other words,

Lawyers with well-developed peripheral vision can be awesome in their ability to look at problems from many different perspectives, to see not only what is presented but what is not presented, to think across doctrinal categories, to spot threat or opportunity originating from outside of what seem to be the boundaries of a problem. ${ }^{51}$

Avoiding narrow and myopic interpretations of any situation or controversy is critical to the lawyer's role in the "real world," and therefore sometimes the peripheral view has a place in the examination as well-recognizing, however, that the exam and its time constraints act as artificial limits on such an exercise and must be respected if one is to complete the assigned task.

Finally, as a note of caution, the "peripheral vision" approach can be taken too far in the context of an exam. The exam taker must be sure to identify her role in relation to the course being tested. For example, if a student is taking a

49 Dewey, supra note 1, at 42.

50 Sallyanne Payton, Is Thinking Like a Lawyer Enough?, 18 U. Мich. J.L. Reform 233, 241 (1985).

${ }^{51} I d$. 
property exam and the fact pattern implicates untaught but related contract doctrines that a student learned in another class, the student should not allow herself to be diverted from the subject being assessed. The property professor will not likely expect nor award points for an answer based on those contract doctrines even if they are accurate and suitable for a contracts exam. Indeed, the property professor may not even be in a position to evaluate the strength of the contracts argument. Moreover, the time spent on the distraction comes with significant opportunity costs to the rest of the exam when the student is operating under a time limit.

\section{F. On the Record Review: Show Your Work-Lessons from Mathematics and the Administrative Procedure Act}

The written exam must demonstrate thought and not simply state its conclusion. Alternatively stated, the submitted exam answer is the thought process memorialized on paper. As Isaac Asimov famously said, "Writing, to me, is simply thinking through my fingers."52 That should be the exam taker's creed. When it comes to an exam, it is not enough to just engage in the exercise of thinking; one must think on paper-extracting from the mind and translating to paper with the pen. The exam taker must be a stenographer creating a transcript of the mind's methods. One cannot presume that the evaluator knows her thoughts, bases, or analyses leading to conclusion unless they are explored in the written answer, the record for review. Consequently, without these things presented in writing, even one operating under an attitude of suspended conclusion cannot prove that she has done so.

This guidance tracks a similar and well-known "show your work" admonition in the field of mathematics classes, ${ }^{53}$ and its application to law school exams is certainly not new to this Article (except for its recognition here as critical to the demonstration of suspended conclusion). Professor Nancy Rapoport, for example, explains that she " $\operatorname{tr}[\mathrm{ies}]$ to remind students about the process of doing 'proofs' of theorems in geometry (or, for those more mathematically inclined, calculus)." 54 She posits that "[t]he necessary skill is the same in both processes. Taking the exam grader step by step through the analysis, instead of making a series of cognitive leaps, makes for a much better (and better rewarded) exam answer." 55 Thus, avoiding those gaps between thought and

52 Wilfred A. Ferrell \& Nicholas A. Salerno, Strategies in Prose: A Thematic READER 182 (Holt, Rinehard, and Winston ed., 5th ed. 1983) (quoting Asimov).

53 As one educator exhorts:

Or consider an example that teachers see frequently: S gets the right answer to a math problem but cannot explain or show how he did it. Most teachers refuse credit in such cases. 'You must show your work!' is a commandment that all students have heard from their math teachers. We, like Socrates, believe that people must have justification for their claim to knowledge.

Nel Noddings, Philosophy of Education 100 (1998); see also Deborah Rumsey, StaTISTICS WorkвOOK FOR Dummies 256 (2005) (explaining the self-serving reasons to show your work to get a better grade); Raffaella Borasi, On the Nature of Problems, 17 Educ. Stud. Mathematics 125, 137 (1986) (discussing problems and the mathematical proof).

54 Nancy B. Rapoport, Is "Thinking Like a Lawyer" Really What We Want to Teach?, 1 J. Ass'N Legal Writing Directors 91, 100 n.28 (2002).

55 Id.; see also, e.g., John C. Dernbach, Writing Essay Exams to Succeed (Not Just to Survive) xxi (2007); Karen L. Koch, A Multidisciplinary Comparison of Rules-Driven 
written answer is critical to a demonstration that the attitude of suspended conclusion, and all that follows it, has been adopted.

Dewey draws a similar analogy and conclusion in his writings. For example, he explains that a thinker operating with a predetermined conclusion is no better than a calculator:

The problem is not to draw a conclusion from given premises; that can best be done by a piece of inanimate machinery by fingering a keyboard. The problem is to find statements, of general principle and of particular fact, which are worthy to serve as premises. As a matter of actual fact, we generally begin with some vague anticipation of a conclusion ... a and then we look around for principles and data which will substantiate it or which will enable us to choose intelligently between rival conclusions. 56

To truly engage in thought one must search for premises and evaluate rival or alternative conclusions rather than expect to punch in data and simply pop out a single answer. It is a matter of testing the suggestions through writing. According to U.S. Circuit Court Judge Kenneth Ripple when explaining his personal observations of Chief Justice Warren Burger, "For the Chief Justice ... the fundamental intellectual process of lawyering and judging occurred when the validity of an initial hunch or intuitive flash was tested by pen meeting legal pad." 57 Exam takers should emulate that disciplined process and clearly adopt that approach in their writing.

Finally, this point is buttressed by using judicial review under the Administrative Procedure Act ("APA") as a model for professorial review in evaluating student written exams. An agency action examined under the APA by a court is "on-the-record review" and unless the agency provides the bases for its

Writing: Similarities in Legal Writing, Biology Research Articles, and Computer Programming, 55 J. Legal Educ. 238 (2005). Another author describes it as thinking of it as math before calculators:

Good Writing is Good Thinking. Before the age of computers and calculators, there was only one way to solve a complex algebra problem: work it out on paper. Unlike students of algebra, however, lawyers have not yet devised the machine that can solve legal problems for them. Like the ancient mathematician, we must, therefore, write out our legal problems if we hope to get the right answer.

Bruce A. Thomason, A Case for Improving Legal Writing, Orange County Law., Oct. 2000, at 36 (emphasis omitted). Yet another author focused on a "no support, no credit" approach to law school exams just as it would be in math class:

Get to the answer through careful study and consideration of all possible options. Each option is fact-and legal theory-tested. No shortcuts. Explain how you get to the answer, why the other options were discarded and why the selected answer is the most appropriate. In short, as we learned in elementary math class, show your work! No credit is given for the right answer if there is no support provided.

Jaime N. Doherty, The Socratic Method Meets the Information Age, Legal InTELligencer, Apr. 13, 2010, at 4 (providing this helpful summary, although ultimately criticizing the utility of traditional law school teaching methods to modern practice).

56 John Dewey, Logical Method and Law, 10 Cornell L.Q. 17, 23 (1925) (emphasis omitted).

57 Kenneth F. Ripple, Legal Writing in the New Millennium: Lessons from a Special Teacher and a Special “Classroom,” 74 Notre Dame L. Rev. 925, 926 (1999) (citing J.C. Hutchinson, Jr., The Judgment Intuitive: The Function of the "Hunch" in Judicial Decision, 14 Cornell L.Q. 272 (1919)). 
conclusions in the record, its action will be invalid. As the U.S. Supreme Court explains in SEC v. Chenery Corporation:

When the case was first here, we emphasized a simple but fundamental rule of administrative law. That rule is to the effect that a reviewing court, in dealing with a determination or judgment which an administrative agency alone is authorized to make, must judge the propriety of such action solely by the grounds invoked by the agency. If those grounds are inadequate or improper, the court is powerless to affirm the administrative action by substituting what it considers to be a more adequate or proper basis. To do so would propel the court into the domain which Congress has set aside exclusively for the administrative agency. ${ }^{58}$

On a traditional law school examination, the student is like the agency and the professor like the court conducting judicial review. Even if the professor knows why the student's answer is correct and can even guess or presume the processes that the student engaged in to reach her conclusion, the professor cannot (or at least many will not) search his mind and "fill in" the reasoning for the student.

The judge conducting judicial review will not look beyond the record, and the agency can only use the rationale that it provides in its decision to support the validity and legality of its action. Drawing again on the APA analogy, the U.S. Supreme Court explains that even when " $[\mathrm{t}]$ here is evidence in the record that might support such a determination[,] . . . the courts will not be expected to scrutinize the record to uncover and formulate a rationale explaining an action, when the agency in the first instance has failed to articulate such rationale."59 Likewise, a student must provide the rationale in the exam itself-he must not presume the reviewer will know the basis for his answer, and an unwritten analysis will not help him contest his grade. ${ }^{60}$

Moreover, in administrative rulemaking the law requires that an agency adequately consider the information available to it before making a decision, and will invalidate as arbitrary and capricious an agency action if the agency had a "predetermined conclusion;" if it is based on such a predetermined conclusion.

The unique character of the exam is that doing is different from demonstrating that a task is done. If the evaluator does not see the analysis on paper, in his eyes the exam writer did not think it.

58 SEC v. Chenery Corp. (Chenery II), 332 U.S. 194, 196 (1947) (emphasis added).

59 Am. Textile Mfrs. Inst. v. Donovan, 452 U.S. 490, 539 n.73 (1981).

60 The prohibition on post-hoc rationalizations requires that an agency state and provide the bases for its decision (i.e., conclusion) before promulgating a rule. Id. at 539 ("Whether these arguments have merit, and they very well may, the post hoc rationalizations of the agency or the parties to this litigation cannot serve as a sufficient predicate for agency action.”); Motor Vehicle Mfrs. Ass'n v. State Farm Mut. Auto. Ins. Co., 463 U.S. 29, 50 (1983) ("Not having discussed the possibility, the agency submitted no reasons at all. The short-and sufficient-answer to petitioners' submission is that the courts may not accept appellate counsel's post hoc rationalizations for agency action."); see also Fed. Power Comm'n v. Texaco, Inc., 417 U.S. 380, 397 (1974); Burlington Truck Lines v. United States, 371 U.S. 156, 168-69 (1962).

61 See, e.g., Ass'n of Nat'l Advertisers v. FTC, 627 F.2d 1151, 1154 (D.C. Cir. 1979). 


\section{G. The "Why" and "Did I Support That Statement" Questions}

The exam taker should read each sentence he writes. If he has not answered on paper the question "why"-why his statement is true, why it is relevant, why it matters - he likely has not yet completed his task. The absence of "because" or "since" may be evidence of the failure to take the next step or make the appropriate connections. That student should edit his answer as he goes and be sure that he asks himself whether the evaluator can find support in the written answer for the statements made. The statement is likely conclusory $^{62}$ if he cannot say "yes" to the question: "Did I provide support for that statement?"63

The exam taker should be especially wary of definitive and declarative statements and conclusions (and the all-too-often used words like "clearly," which are red flags that the student is likely about to make a conclusory statement). ${ }^{64}$ If he is about to say something like "clearly," the student better be sure he has already made the answer clear somewhere other than in his head, such as in the preceding written analysis and after disposing of alternative or rival conclusions-especially because so few controversies (especially those crafted in law school exam hypotheticals $)^{65}$ have one clear answer. ${ }^{66}$

62 A "conclusory" statement is one "that puts forth a conclusion but not the reasoning behind it." Bryan A. Garner, The Redbook: A Manual on Legal Style 226 (2d ed. 2006).

${ }^{63}$ Moreover, a conclusory statement likely will result in missing a large portion of the available points from expected analysis in the answer.

${ }^{64}$ Patrick Wiseman, "When You Come to a Fork in the Road, Take It," and Other Sage Advice for First-Time Law School Exam Takers, 22 GA. ST. U. L. REv. 653, 661 (2006) ("That brings me to another important piece of advice: Do not jump to conclusions. . . . [Y] ou should at least consider the possibility that the conclusion you've reached is not the only possible conclusion. For every declarative sentence you write, at the very least think 'on the other hand . . ' and think it seriously.").

65 See supra text accompanying notes 46-48.

66 See generally, e.g., Bradley G. Clary \& Pamela Lysaght, Successful Legal AnalYSIS AND WRiting: The Fundamentals 102 (2d ed. 2006) (“[A]void exaggeration through conclusory modifiers such as 'clearly,' 'plainly,' 'very,' 'obviously,' 'outrageous,' 'unconscionable,' and the like.”); Linda H. Edwards, Legal Writing AND ANALysis 283 (3d ed. 2011) ("Because generations of writers have overused words like 'clearly' or 'very,' these and other common intensifiers have become virtually meaningless. As a matter of fact, they have begun to develop a connotation exactly opposite their original meaning."); GARNER, supra note 62, at 224 (describing "clearly" and "obviously" as "weasel words" that "reassure the writer but not the reader. If something is clearly or obviously true, prove it to the reader without resorting to the conclusory use of these words."); Richard K. NEumanN, JR., LEGAL Reasoning and Legal Writing: Structure, Strategy, and Style 330 (5th ed. 2005) (““'OO]bvious' and 'clearly' supply no extra meaning.”); Lance N. Long \& William F. Christensen, Clearly, Using Intensifiers is Very Bad-or is it?, 45 IdAho L. Rev. 171, 172 n.3 (2008) (testing the effectiveness of intensifiers in legal argument, citing, inter alia: MARY Beth Beazley, A Practical Guide to Appellate Advocacy 194 (2d ed. 2006) ("Clearly, obviously, of course, and it is evident that have been so over-used that they go beyond having no meaning to having a negative meaning.")). 


\section{H. Anticipate and Argue All Sides; Use Alternative Analysis; Compare, Contrast, and Weigh}

One cannot properly adopt an attitude of suspended conclusion unless he seriously considers rival suggestions and alternative arguments. One must examine these alternative or rival hypotheses to a problem in order to "prevent[] [one] from dogmatically accepting the first suggestion" so that "[j]udgment is held in suspense and a positive conclusion postponed." 67 The alternative suggestions approach should be adopted by the prudent exam taker, and the arguments favoring that approach were already substantially advanced in Part I of this Article. Nonetheless, a few additional comments on the approach are helpful here.

The effective implementation of the attitude of suspended conclusion in the exam setting demands that the student explore (on paper, of course) all sides of an argument, all positions of all interested parties, all potentially triggered "issues," and all potentially applicable doctrines (such as majority and minority rules) in the scenario presented to him. ${ }^{68}$ The student must consider Dewey's forked-road situation and apply it to these alternative arguments and rival conclusions or suggestions, which one commentator describes thus:

If there's more than one rule applicable to a particular fact, you've reached a fork in the road. Take it, i.e., apply the one rule and follow where it leads you. Then apply the other rule and see if it leads you somewhere different. You are essentially constructing a decision tree with every branch made explicit. ${ }^{69}$

This forked-road approach should be extended to problems where there is a minority rule and majority rule, and where there is room for rival application of rules, theories, arguments, or other suggestions and conclusions.

Whenever such rival options are present-and they almost always are on law school exams - the analysis requires that they be analyzed with comparison and contrast:

Comparison, without contrast, does not amount to anything logically. . . . Unless, in short, the observer takes care to have the differences in the observed cases as extreme as conditions allow, and unless he notes unlikenesses as carefully as likenesses, he has no way of determining the evidential force of the data that confront him.

Another way of bringing out this importance of unlikeness is the emphasis put by the scientist upon negative cases - upon instances which it would seem ought to fall into line but which as matter of fact do not. Anomalies, exceptions, things which agree in most respects but disagree in some crucial point, are so important that many of the devices of scientific technique are designed purely to detect, record, and impress upon memory contrasting cases. ${ }^{70}$

One can only compare and contrast if she started with a state of doubt that allowed for the formulation of a list of possible alternatives. While for purposes

67 Dewey, supra note 1 , at 82.

68 Analysis of Reflective Thought, supra note 7, at 36 ("If one hypothesis is good because it starts one train of deductive implications and initiates one set of experiments, several are better because they extend the operation. In any complicated case, it would be practically impossible to arrive at a sound conclusion save as various deductive systems were compared and the results of different experiments used to check one another.").

69 Wiseman, supra note 64, at 662 (emphasis omitted) (footnote omitted).

70 Dewey, supra note 1, at 89-90 (emphasis omitted). 
of dispassionate evaluation of a problem one must suspend conclusion, even when one is tasked to support a specific side by the evaluator, it is useful to first understand alternative arguments,${ }^{71}$ which can be accomplished by suspending momentarily the role as an advocate for one side.

The exam taker must weigh the alternative arguments, and evaluate the strength of each party's case in light of the respective opposition. Good lawyering requires the same. Even when one must zealously advocate for her client, an effective thinking technique involves the ability to recognize all arguments, particularly those of the opposition. The ability, then, to be able to articulate what the opposition's argument will look like and describe how it will be supported is a necessary step to know how it can be countered. Useful advice in this regard comes from Professor Kathryn Stanchi, who explains that "[c]onfronting and defusing negative information is a critical aspect of the art of persuasion"72 in part "because "[t]he weight of an argumentative position can be properly gauged only by reference to what can be set against it.",73 Stanchi continues with an instrumental reason for conducting this counterargument in an analysis - an argument is stronger when "it confronts and refutes its weaknesses," and "studies show a distinct advantage for a message that directly and frankly deals with negative information." " Stanchi's focus is on improving advocacy, but its lesson applies equally to the exam taker or other problem solver operating from a dispassionate and uncommitted position and starting with an attitude of suspended conclusion.

After fully explaining the arguments available to all sides and the alternative conclusions through the process of comparing and contrasting those arguments and conclusions, the exam taker should assess the strength of each and be sure that she has fully developed the argument for the choice of one over the other. And, of course, all of this must be on paper or else the student will fail to provide the full and rich written answer that provides the proof of suspended conclusion. ${ }^{75}$

\section{Be the Judge: Reach a Reasoned Conclusion at the End and Not Before}

Take a stand-at the end and not before. The effective exam taker will eventually reach a conclusion, but only after suspension and the analysis that follows it. Knowing when to stop is guided by the level of analysis demanded as described in previous sections above, responsible judgment on the part of the thinker as to when enough is enough, and external limitations (like time constraints) that are beyond the exam taker's control. The existence of time pres-

71 McElory \& Coughlin, supra note 36, at 229 ("[I]f [students] predict that their client will prevail, they need to remember that the court could logically reach the opposite conclusion.").

72 Kathryn M. Stanchi, Playing With Fire: The Science of Confronting Adverse Material in Legal Advocacy, 60 Rutgers L. Rev. 381, 381 (2008).

73 Id. at 388 (quoting C. Geoffrey Hazard Jr., Arguing the Law: The Advocate's Duty and Opportunity, 16 GA. L. Rev. 828 (1982)). See also McElroy \& Coughlin, supra note 36, at 230 (noting that "the logically strongest overall conclusion" requires students "to "critically evaluate arguments and counterarguments," " and "it 'enhances the writer's credibility as an intelligent source of information" " (footnote omitted)).

74 Stanchi, supra note 72 , at 424.

75 See supra text accompanying note 53. 
sure in an exam necessitates an orderly progression and conclusion within the allotted time and the student must manage his answer and response to that pressure cautiously. There can be dangers for law students as well as others in exploring too much or for too long, and the good thinker will retain an awareness of those risks. Closure is necessary at some point, of course, in a law school exam or in reaching finality to a problem where, for example, an official is faced with an institutional duty to reach final judgment on a case.

Dewey explains in How We Think that "[t]he disciplined, or logically trained, mind - the aim of the educative process - is the mind able to judge how far each of these steps needs to be carried in any particular situation," and describes when to stop and reach a conclusion or when to continue with the reflective process. ${ }^{76}$ Elsewhere, Dewey responds to some criticisms of the attitude of suspended conclusion, explaining that it should not be seen as an endorsement for decision avoidance or perpetual indecision. "It is far from being true . . . that conclusion is postponed till the problem is solved. We accept or adopt at every point. The difference is in the conditions and purpose of the acceptance ...."77

Even where the right conclusion is not evident after weighing competing arguments, in most circumstances it is appropriate on an exam to come to a conclusion at the end of the exam enterprise based on the available data as analyzed and critically examined within the available time or deadline. Because most exams have a relatively closed set of data and relevant law, it should be easier to accomplish this task within a deadline than it would be in other life situations where the data set may be relatively open and where time constraints may not exist or the failure to meet a deadline may have less devastating consequences. A student, however, does not have the luxury to linger too long.

One caution to the "conclude at the end and not before" statement above is necessary here. Some professors will prefer that the exam taker concisely state his conclusion at the outset of his answer. Again, in all cases the student is well advised to adapt his approach to the expectations of the particular evaluator. However, putting a conclusion on paper at the beginning of an answer is wrought with the peril of becoming tunnel-visioned or unwisely constrained to that conclusion for the rest of the student's written answer. It risks one losing the benefits of suspending conclusion. To avoid that risk, the student should leave space in her answer at the top, and fill in that first sentence after completing the rest of the answer. Or, the student must ensure that the analysis that follows a conclusion adequately includes all of the elements necessary to support that conclusion (including the examination and informed dismissal of rival conclusions).

\section{J. Intake Lawyer Approach; Positioning the Problem and Outlining the Answer}

One technique for a law student approaching a traditional-style law school exam hypothetical is to consider himself an intake attorney, with the potential client providing a narrative of events. Everything the client says is an input in

76 Dewey, supra note 1, at 78.

77 Analysis of Reflective Thought, supra note 7, at 37 n.4. 
the reflective thinking process - a data point for the analysis of the situation. It is the body of raw material from which the thinker must operate. Each line, as read (or heard) should evoke questions in the intake attorney such as: Why might this become relevant? What legal rules might be triggered by the appearance of that fact? How might this information be useful? How does that help or hurt the client in light of the law likely involved? What more would I want to know, and what questions should I ask if not answered by the end of the narrative? What is the stage of the case at this intake juncture? What has happened before, what is happening now, and what can be done next?

Most statements in the hypothetical have some utility to the expected answer. If the exam is well crafted, the evaluator typically will not include superfluous information. By taking in the facts as they come and simultaneously exploring individually how a particular statement fits in the expected answer-what might be called a line-by-line inquiry - the student can be cautious and methodical and avoid missing an important consequence of any particular statement to the overall situation presented. By adopting this intake lawyer approach, the exam taker is compiling the inputs and positioning them in the problem, and she is positioning her learned material in with it as well. That process is best followed with an organization of that material and an outline of an answer.

\section{K. The "What is Next?" Question}

The exam taker's role may be limited to the evaluation of just one setting or the context of only one part of the legal world, but the student must be capable of strategizing another approach should that initial one fail to satisfy the preferences of her client. In a similar vein, the student/lawyer should be able to anticipate the opposition's next steps when that opponent loses and will seek another avenue for her client. A loss may not mean the end of the pursuit. The war may still be ongoing, with future battles awaiting the represented interest. A professor may or may not expect that the student demonstrate an understanding of the landscape after the immediate dispute is resolved. Whether students should place a "what's next" analysis at the end of an essay will depend on their evaluator's preference. Nonetheless, a good student with a comprehensive approach should at least make it a practice to ask the "what's next" question and not drop into a lull of complacency once the immediate situation is resolved. If for no other reason, a student should learn to determine whether her client still needs further assistance lest she lose a future employment opportunity that might be available from the suggestion of a new and next step.

\section{Conclusion}

From these selected points of guidance, the exam taker's ability to make the attitude of suspended conclusion effective in operation during an exam should be enhanced. It is important to restate that what is discussed above is not an exhaustive list of guidance, nor is it necessarily fitting in all exams. Students must be sure to check these suggested approaches against their particular evaluators' preferences. 
Law students should apply some of this guidance to their writing exercises outside the exam process, too. Moreover, each of these principles is equally applicable to a lawyer's general thinking processes and writing approach. If the practicing attorney filters her writing through each of these rules she will become more effective, reasoned, and persuasive, and demonstrate on paper comprehensive processes of thought.

If a student looks closely at each of these points of guidance to exam taking, she should see that, without employing these approaches, the attitude of suspended conclusion cannot truly operate effectively on a law school essay exam. Similarly, anyone interested in the mechanics of the attitude of suspended conclusion and anyone engaged in problem-solving activities should glean valuable insights into its meaning and operation from the case example of the traditional law school exam. Only by suspending conclusion can one open herself up to the opportunity of reflective thinking, which leads to more effective answers to critical problems. 